\title{
Statins as Pleiotropic Modifiers of Vascular Oxidative Stress and Inflammation
}

\author{
Costas Psarros¹, Evangelos K. Economou¹, Michael Koutsilieris¹, Charalambos \\ Antoniades ${ }^{2 *}$ \\ ${ }^{1}$ Department of Experimental Physiology, Medical School, National and Kapodistrian University of Athens, Greece \\ 2 Radcliffe Department of Medicine, Cardiovascular Medicine Division, University of Oxford, John Radcliffe Hospital, \\ Oxford, United Kingdom.
}

\begin{abstract}
Cardiovascular disease (CVD) is the leading cause of morbidity and mortality in the industrialized world and in the future is expected to be the number one killer worldwide. The main cause underlying CVD is atherosclerosis. A key event in atherosclerosis initiation and progression is oxidative stress through the production of reactive oxygen species as well as endothelial dysfunction. Several pro- inflammatory and anti-inflammatory cytokines and proteins are involved in this process, complemented by activation of adhesion molecules that promote leukocyte rolling, tethering and infiltration into the sub-endothelial space. Statins represent the agent of choice since numerous clinical trials have verified that their pharmacological action extends beyond lipid lowering. Statins demonstrate direct anti-oxidant effects by scavenging free radicals and stimulating anti-oxidant enzymes while acting as regulators for cytokine, protein and adhesion molecule expression, all of which are involved in the atherosclerotic process. Statin use is considered one of the most efficient currently used interventions in managing CVD with the likely hood of remaining so in the near future.
\end{abstract}

Keywords: atherosclerosis, adhesion molecules, cardiovascular disease, interleukins, inflammation, oxidative stress, statins

Received: 18 March 2015 / Accepted: 20 April 2015

\section{CARDiovascular disease}

Cardiovascular disease (CVD) is the leading cause of death in the Western world and by 2020 it is estimated that it will be the leading cause of mortality worldwide. The main cause underlying the development of CVD is atherosclerosis. The understanding of the pathophysiology of atherosclerosis has evolved over the last few decades. Previously considered as a lipid storage disease, atherosclerosis is now perceived as a low-grade inflammatory disease of the vascular wall that leads, through various processes, to the formation of atherosclerotic plaques (figure 1). Oxidative stress plays a key role in this process as it promotes oxidation of low density lipoprotein (ox-LDL). This acts as a potent chemoattractant enabling the recruitment of T-cells and monocytes to the inflamed areas and their penetration into the sub-endothelial space where they uptake ox-LDL. Eventually macrophages transform into foam cells through several biochemical pathways. Over time atherosclerotic plaques are formed, leading initially to narrowing of the lumen and subsequently to occlusion of the vessel. Under certain conditions, mainly due to the presence of pro-inflammatory cytokines and proteases, plaques can become unstable or even rupture. In these occasions the lipid cap of the plaques, which is highly pro-coagulant, results in clinical manifestations such as stroke, acute myocardial infraction (AMI) or acute vascular syndromes, depending on the area affected.

\footnotetext{
* Correspondence to: Professor Charalambos Antoniades, Radcliffe Department of Medicine, Cardiovascular Medicine Division University of Oxford, West Wing L6 John Radcliffe Hospital, Headley Way, Oxford OX3 9DU, United Kingdom; e-mail: antoniad@well.ox.ac.uk
} 


\section{OXIDATIVE STRESS AND ENDOTHELIAL}

\section{DYSFUNCTION IN ATHEROSCLEROSIS}

Oxidative stress is termed as the imbalance between the production of reactive oxygen species (ROS) and the system's ability to detoxify them [1]. Aberrant production of ROS has been associated with most of the classical risk factors responsible for the initiation and progression of atherosclerosis. These include, among other things, diabetes mellitus, smoking and hypertension [2]. As aforementioned the key event in the atherosclerotic process is the oxidation of LDL to ox-LDL in the areas of inflammation. This event takes place mostly in the sub-endothelial space and not within the circulatory system. LDL contains several different types of particles including phospholipids, free cholesterol, triglycerides and cholesteryl esters [3]. The polyunsaturated lipids can undergo oxidation, forming several by-products, such as aldehydes, like malon- dialdehyde (MDA), which in turn react with the lysine and tyrosine amino acid residues of the apolipoprotein B-100, thus impairing its function. The result is the formation of minimally modified LDL, which exerts highly pro-atherogenic actions. This can be recognized by LDL but not by scavenger receptors. Nicotinamide adenine dinucleotide phosphate (NADPH) is also a key contributor of superoxide radicals in endothelial cells. Furthermore, LDL has been known to activate NADPH oxidase, which in turn oxidizes LDL, creating a vicious circle. Oxidative stress also has a critical impact on several redox-sensitive transcriptional pathways such as the nuclear factor kappa-light-chain-enhancer of activated B cells (NF- $\kappa \mathrm{B})$ and the transcription factor AP-1 [2], both of which are involved in atherogenesis. It has recently been shown that products secreted from perivascular adipose tissue, such as adiponectin, can have paracrine and endocrine effects on the arterial wall by attenuating NADPH-oxidase activity and en-

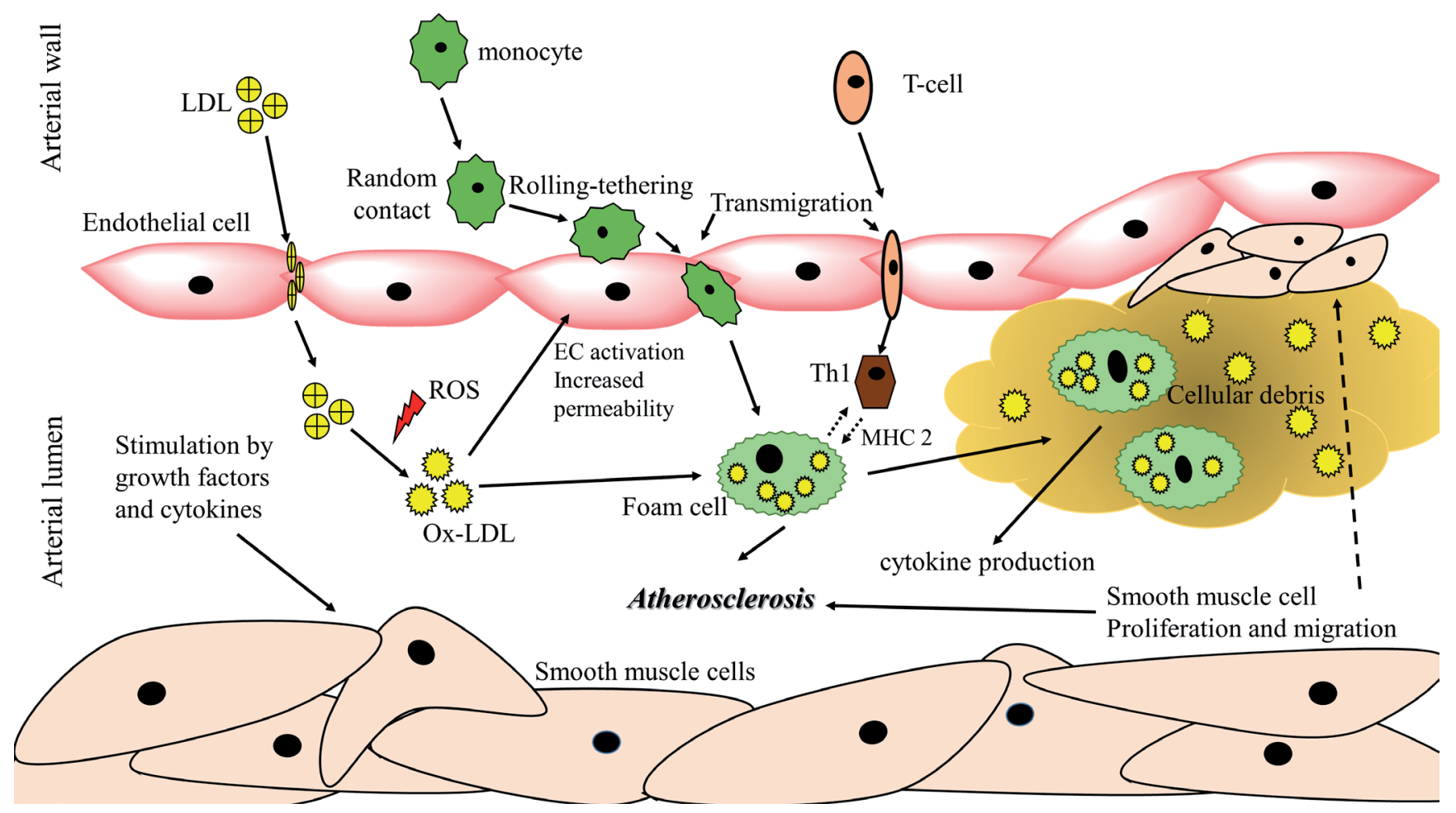

Figure 1. Key mechanisms involved in the progression of atherosclerosis. Initially low-density lipoprotein enters into the sub-endothelial space, where under the effect of reactive oxygen species it is oxidized into ox-LDL. This results in activation of the endothelium which subsequently leads to facilitated transmigration of leukocytes and T-cells. The former uptake ox-LDL and turn into foam cells, while the latter differentiate into Th1 cells. These events favour the production of pro-inflammatory cytokines, which in combination with various growth factors stimulate smooth muscle cell proliferation and migration into the sub-endothelial space as a response to vascular injury, contributing to fibrous cap formation. Abbreviations: EC: Endothelial Cell, LDL: Low density lipoprotein, MHC 2: major histocompatibility complex) class II, Ox-LDL: Oxidized low density lipoprotein, ROS: Reactive oxygen species. 
dothelial nitric oxide synthase coupling in human atherosclerosis. This highlights the novel role of adipose tissue as a regulator of vascular redox state [4-7].

Another key event in the initiation of atherosclerosis is endothelial dysfunction. This process involves the reduction of the availability of nitric oxide (NO), a gaseous molecule that once diffused in the vascular smooth muscle cells (VSMC), inducing vasorelaxation via intracellular cyclic guanosine monophosphate (cGMP) increase. The major enzymatic source of NO production is endothelial nitric oxide synthase (eNOS), located primarily in endothelial cells. This enzyme is a homodimer that utilizes l-arginine and molecular oxygen as substrates to produce $\mathrm{NO}$ and l-citrulline [8]. The reaction uses nicotinamide adenine dinucleotide phosphate (NADPH) as an electron donor. The electron flow is increased by the presence of calmodulin, which in turn is mediated by calcium binding. In order for this process to take place the presence of tetrahydrobiopterin $\left(\mathrm{BH}_{4}\right)$ is imperative. The limiting enzyme for the $\mathrm{BH}_{4}$ synthesis pathway is the enzyme guanosine triphosphate cyclohydrolase (GTPCH). Under physiological conditions $\mathrm{BH}_{4}$ is "coupled" to eNOS in order for NO to be produced. However, ROS and more specifically peroxynitrite (ONOO-) lead to "uncoupling" of the enzyme, causing a dissociation of its complex and shifting of the production from NO to superoxide radicals $\left(\mathrm{O}_{2}^{-}\right)$[9]. These rapidly react with NO forming $\mathrm{ONOO}^{-}$which further oxidizes $\mathrm{BH}_{4}$ to dihydrobiopterin $\left(\mathrm{BH}_{2}\right)$ creating a loop by further eNOS uncoupling [10]. This results in further reduction of NO availability, greatly affecting the ability for vasorelaxation thus impairing proper endothelial function [11]. Genetic polymorphisms in eNOS have been associated with a higher risk of premature myocardial infraction by affecting the inflammatory response [12]. Furthermore, 5-methyltetrahydrofolate (5-MTHF) was shown to rapidly improved endothelial function and vascular superoxide production in human atherosclerosis, by preventing peroxynitrite-mediated $\mathrm{BH}_{4}$ oxidation and improving eNOS coupling [13]. Previous studies revealed that asymmetrical dimethylarginine (ADMA), an endogenous inhibitor of eNOS was associated with important measures of vascular function in human vessels [14-16]. Recent research has also revealed the important role of perivascular adipose tissue and its interaction with the vascular wall, highlighting the role of adiponectin as a regulator of $\mathrm{BH}_{4}$ bioavailability and eNOS activation in human vessels [6].
PRO-INFLAMMATORY AND ANTI-INFLAMMATORY CYTOKINES AND PROTEINS IN ATHEROSCLEROSIS

Cytokines are small molecules that mediate cell signalling in an autocrine/paracrine manner. They can be subcategorized into several families with distinct actions. Cytokines play important roles in both early and later stages of the atherosclerotic process [17]. They can also induce the up-regulation of adhesion molecules [15-18].

\section{Interleukin-6}

Interleukin-6 (IL-6) is a pro-inflammatory cytokine produced by different cell types including adipocytes [19-21]. In healthy individuals, IL-6 is regulated by a complex hormonal network related to glucocorticoid and catecholamine secretion. Increased IL-6 expression and circulating levels have been associated with a variety of pathological conditions such as vascular disease, central obesity, metabolic syndrome, atherosclerosis and atherosclerotic coronary artery disease (CAD) [20-21]. IL-6 is a key risk factor for the development of atherosclerosis mainly due to its effect on plaque development and destabilization through the release of other pro-inflammatory cytokines, oxidation of lipoproteins by phospholipases, stimulation of acute phase protein secretion and release of pro-thrombotic mediators [20-22]. Furthermore, increased reactive oxygen species (ROS) formation under pro-inflammatory conditions, may play a critical role in the interactions between IL- 6 and other vasoactive substances such as angiotensin II and catecholamines [23-24]. Increased levels of IL-6 have been associated with elevated levels of adhesion molecules. Furthermore IL- 6 travels to the liver and induces the acute-phase response, resulting in synthesis and release of the aforementioned proteins [18].

\section{Interleukin-1 $\beta$}

Interleukin-1 $\beta$ (IL-1 $\beta$ ) is a pyrogenic cytokine produced mainly by monocytes. It is usually produced as a result of an infection, immune or injury response [25]. Even low concentrations of IL- $1 \beta$ can cause fever and hypotension, while at the same time stimulating the production of additional cytokines, such as IL- 6 . It is part of the IL-1 family, which also includes IL-1a and IL-1 receptor antagonist (IL-1Ra). Recently, due to structural and amino acid sequence similarities, 
other interleukins have been added to this group, notably IL-18 and IL-33 [26-27]. Synthesis and circulation levels of IL- $1 \beta$ are tightly regulated at all stages of IL$1 \beta$ production. This ranges from the expression of the IL-1B gene, the production of the $35 \mathrm{kDa}$ pro-IL- $1 \beta$, to its cleavage that yields the $17 \mathrm{kDa}$ mature product [28]. Several molecules such as caspase 1 inhibitor proteinase inhibitor 9 (PI-9), pyrin, ICEBERG and CARD-only protein (COP) are involved in this process, by either directly neutralizing caspase 1 activity or by inhibiting its recruitment [25].

\section{Interleukin-10}

Human interleukin-10 (IL-10) is an $18.5 \mathrm{kDa}$ protein composed of 160 amino acids and is encountered as a homodimer with a molecular weight of $37 \mathrm{kDa}$. $\mathrm{Hu}-$ man and murine IL-10 share a homology of approximately $80 \%$. There are several cells able to synthesize IL-10 [29] including macrophages, monocytes and T and B cells. It is structurally related to five other human molecules, IL-19, IL-20, IL-22, IL-24 and IL-26. IL-10 exhibits significant anti-inflammatory effects and acts via a feedback loop as a response to excessive inflammatory effects. Its primary role in atherosclerosis is to inhibit macrophage activation via NF-Kb signalling and cell death as well as to attenuate production of matrix metalloproteases (MMPs) and pro-inflammatory cytokines [30]. There is also recent evidence that macrophage produced IL-10 also facilitates cholesterol metabolism in the same cells [31].

\section{Interleukin-18}

Interleukin-18 (IL-18) is a pleiotropic pro-inflammatory cytokine with a pivotal role in the inflammatory cascade. It shares a homology with IL- $1 \beta$ and exists as a $25 \mathrm{kDa}$ pro-peptidemwhich is cleaved to yield the 18 $\mathrm{kDa}$ biologically active mature molecule [32]. IL-18 can enhance $\mathrm{T}$ and natural killer (NK) cell maturation as well as increase cytokine production. Having strong immunomodulatory effects, it is also a key molecule for orchestrating the host defence systems against various infections. This is achieved at multiple points and by activation of cytokine cascades [32]. IL-18 has also been related to vascular events in patients with stable or unstable angina or coronary heart disease (CHD) [33-34].

\section{C-reactive Protein}

C-reactive protein (CRP) is an acute phase protein with a pivotal role in immunity. It is composed of five identical subunits arranged in a cyclic symmetry [35]. Given the fact that recent techniques measuring CRP utilize high sensitivity methods, it is also commonly referred to as high sensitivity CRP (hs-CRP). It is synthesized in the liver, after stimulation by IL-6, and then secreted into the circulation. CRP is also expressed in macrophages, atherosclerotic plaque tissue and VSMCs [36-37]. In cases of low-grade inflammation, such as in atherosclerosis, CRP levels increase [36] and due to CRP having a half-life of 19 hours, elevated levels can be detected in serum [38]. Other studies have demonstrated a link between elevated levels of hs-CRP and CVD [39]. Its long half-life, combined with its resilience to several freeze-thaw cycles, establishes CRP as a reliable biomarker with high accuracy and reproducibility [40]. A disadvantage lies in the fact that CRP is nonspecific, hence elevated levels of CRP due to other factors, such as illness and infection might lead to false positive results [40].

\section{Serum Amyloid A}

Serum amyloid A (SAA) is another acute phase response protein synthesized in the liver as a response to tumour necrosis factor (TNF), IL-1 and IL-6 cytokine stimulation [41]. The SAA family consists of isoforms SAA-1 and SAA-2 as well as a constitutive SAA-4 isoform. In humans, SAA-3 isoform does not appear to participate in the acute phase response, despite sharing $60 \%$ homology with its acute phase counterparts. During an acute phase event, SAA levels may rise 100-1000 fold and return to baseline within 2 weeks. During this phase SAA is the primary apolipoprotein for high density lipoprotein (HDL), taking the position of apoA 1 . Rapid elevation of SAA levels is due to transcriptional and post-transcriptional regulation of isoforms SAA1 and SAA-2 [41]. There are studies highlighting the association between low-grade inflammation and elevated levels of SAA [42].

\section{Lipoprotein-associated Phospholipase $A_{2}$}

Lipoprotein-associated phospholipase $\mathrm{A}_{2}$ (Lp-PLA ${ }_{2}$ ), also termed platelet-activating factor acetylhydrolase (PAF-AH), is an enzyme that belongs to the $\mathrm{PLA}_{2}$ superfamily. It has a unique role in cleaving oxidized phospholipids, as its acts through a diverse catalytic pathway, accessing the substrate from the aqueous phase [43]. Given the fact that Lp-PLA ${ }_{2}$ cleaves oxidized phosphatidylcholine produced during the oxidation of LDL and lipoprotein(a) (Lp(a)), several pro- 
inflammatory and pro-apoptotic lipid products are created, promoting atherosclerotic plaque formation [44]. Lately several studies demonstrate that Lp-PLA can be used as an independent risk marker for predicting acute coronary syndromes, myocardial infraction and death, as elevated serum levels correlated with the severity of the disease [45].

\section{ADHESION MOLECULES IN}

\section{ATHEROSCLEROSIS}

The release of cytokine and chemokine triggers the over-expression of leukocyte adhesion molecules by endothelial cells (ECs), most notably selectins (P-, Eand L-) and immunoglobulin-like molecules. These are the intracellular adhesion molecules (ICAMs), ICAM1, ICAM-2, ICAM-3, vascular cell adhesion molecule-1 (VCAM-1) and platelet endothelial cell adhesion molecule (PECAM-1) [46].

\section{Selectins}

Selectins are C-type lectins sharing a conserved structure and mediate capture, rolling and tethering on the endothelium [47]. L-selectin is expressed by circulating leukocytes and mediates $\mathrm{T}$ and B lymphocyte trafficking and homing in areas of chronic inflammation [48]. It is also involved in the capture of flowing leukocytes to rolling ones on the endothelium, also known as secondary capture [49]. P-selectin is present in atherosclerotic endothelium but is not found on non-inflamed endothelium. Ox-LDL and minimally modified LDL (mmLDL) activate P-selectin expression which in turn promotes monocyte adhesion to the endothelium [50]. Studies have also demonstrated that P-selectin is expressed at the beginning of the atherosclerotic process [51]. E-selectin can be found on both cytokine stimulated ECs and on the surface of fibrous lipid rich atherosclerotic plaques [52-53]. It is synthesized only under inflammatory conditions and not by healthy non-inflamed endothelium.

The mechanisms under which selectins are downregulated and removed after cell activation are of great importance, as this is required to terminate the inflammatory process. Inability to do so has detrimental effects on the inflammatory process and on vascular wall integrity. P- and E- selectins are removed through internalization and lysosomal degradation, whereas L- and E-selectin can undergo proteolytic cleavage [54]. As a result, soluble forms of these molecules may be found in the circulation and may interact with their normal counter-receptors. All selectins interact with sialylated and highly fucosylated carbohydrates in addition to possessing an affinity for mucin-like glycoproteins. As a result of interaction with their ligands, selectins create weak bonds with the active ECs and leukocytes promoting inflammation and thrombus formation [46].

\section{Immunoglobulin-Like Molecules}

Members of the immunoglobulin family, including glycoprotein membrane receptors with extracellular Ig domains of 70-100 amino acids, are present at adhesion sites. Genes of this family give rise to multiple isoforms as a result of alternative splicing.

\section{Intercellular Adhesion Molecules}

Intercellular Adhesion Molecules (ICAMs) belong to a subfamily of five members, although only ICAM $-1,-2$ and -3 participate in the inflammatory process. ICAM-1 is regulated by pro-inflammatory stimuli (i.e. ox-LDL) and in turn regulates monocyte adhesion to the activated endothelium. ICAM-2 is detected in leukocytes, platelets and the endothelium with inflammatory mediators down-regulating its expression. ICAM3 is present in leukocytes and ECs and is also the sole ICAM family member found in neutrophils $[46,50,55]$. Common ligands for ICAM molecules are $\beta 2$ integrins although each ICAM molecule can bind to multiple ligands by utilizing different binding domains. The strong bonding between ICAMs and integrins allows for firm attachment of inflammatory cells to ECs [56].

\section{Vascular Cell Adhesion Molecule-1 and Platelet En- dothelial Cell Adhesion Molecule}

Vascular Cell Adhesion Molecule-1 (VCAM-1) is primarily expressed on ECs although it can also be expressed by other cell types, including macrophages, dendritic cells and myoblasts. It aids in the recruitment of blood cells by firmly binding them to the activated endothelium. It interacts with integrin $\alpha 4 \beta 1$, also referred to as very late antigen 4 (VLA4), through a process by which a change in endothelial cell morphology is initiated allowing for leukocyte migration [57]. VCAM-1 over-expression is affected by proatherogenic molecules such as ox-LDL. Proteolytic cleavage of VCAM-1 gives a soluble form (sVCAM-1) which can be a strong independent biomarker for predicting future fatal cardiovascular events in patients with CAD [58]. 
Another member of the Ig family is the platelet endothelial cell adhesion molecule (PECAM-1). It is expressed by haematopoietic, immune and ECs [59]. PECAM-1 molecules can be involved in both homophilic and heterophilic interactions, the former taking place in adjacent cells and the latter mostly on the same one [60]. PECAM-1 plays a key role in leukocyte transmigration which is achieved in multiple ways. In addition, the role of PECAM-1 has been investigated in several disease models such as ischemia/reperfusion injury, atherosclerosis and other inflammatory diseases [59].

\section{Junctional Adhesion Molecules}

Junctional adhesion molecules (JAMs) represent another branch of the Ig family and are normally located in the intracellular junctions of polarized endothelial and epithelial cells but can also be encountered on leukocytes and platelets. They are involved in homophilic and heterophilic cell interactions and regulate diapedesis of leukocytes to tissues [61]. There is evidence that JAMs participate in atherosclerosis as JAM-A over-expression has been reported in atherosclerotic plaques of patients suffering from CVD [62]. In addition, JAM-A has been implemented in the recruitment of $\mathrm{T}$ cells and monocytes into arteries [63]. JAM-A deficiency is associated with significant reduction in neo-intimal lesion formation after wire injury of carotid arteries. JAM-B was reported to interact with very late antigen-4 (VLA4) and most likely be associated with leukocyte homing [64]. JAM-C has a role in early atherosclerosis and is also up-regulated by ox-LDL [65].

Table 1. Overview of the pharmacological and chemical properties of statins

\begin{tabular}{|c|c|c|c|c|c|c|}
\hline Name & Chemical structure & Derivation & Solubility & $\begin{array}{c}\text { Metabolic } \\
\text { pathway }\end{array}$ & $\begin{array}{c}\text { Bio- } \\
\text { availability }\end{array}$ & $\begin{array}{c}\text { Half-life } \\
\text { (hours) }\end{array}$ \\
\hline Atorvastatin & & Synthetic & lipophilic & CYP450 3A4 & $14 \%$ & 14 \\
\hline Pitavastatin & & Synthetic & lipophilic & $\begin{array}{c}\text { Biliary, } \\
\text { CYP2C9/2C8 }\end{array}$ & $50 \%$ & 12 \\
\hline Pravastatin & & $\begin{array}{c}\text { Fermentation } \\
\text { derived }\end{array}$ & hydrophilic & Non CYP & $17 \%$ & 77 \\
\hline Rosuvastatin & & Synthetic & hydrophilic & $\begin{array}{l}\text { CYP2C9, } \\
\text { CYP2C19 }\end{array}$ & $20 \%$ & 19 \\
\hline Simvastatin & & $\begin{array}{l}\text { Synthetic deriva- } \\
\text { tive of a fermen- } \\
\text { tation derived } \\
\text { product }\end{array}$ & lipophilic & CYP450 3A4 & $<5 \%$ & 1.9 \\
\hline
\end{tabular}




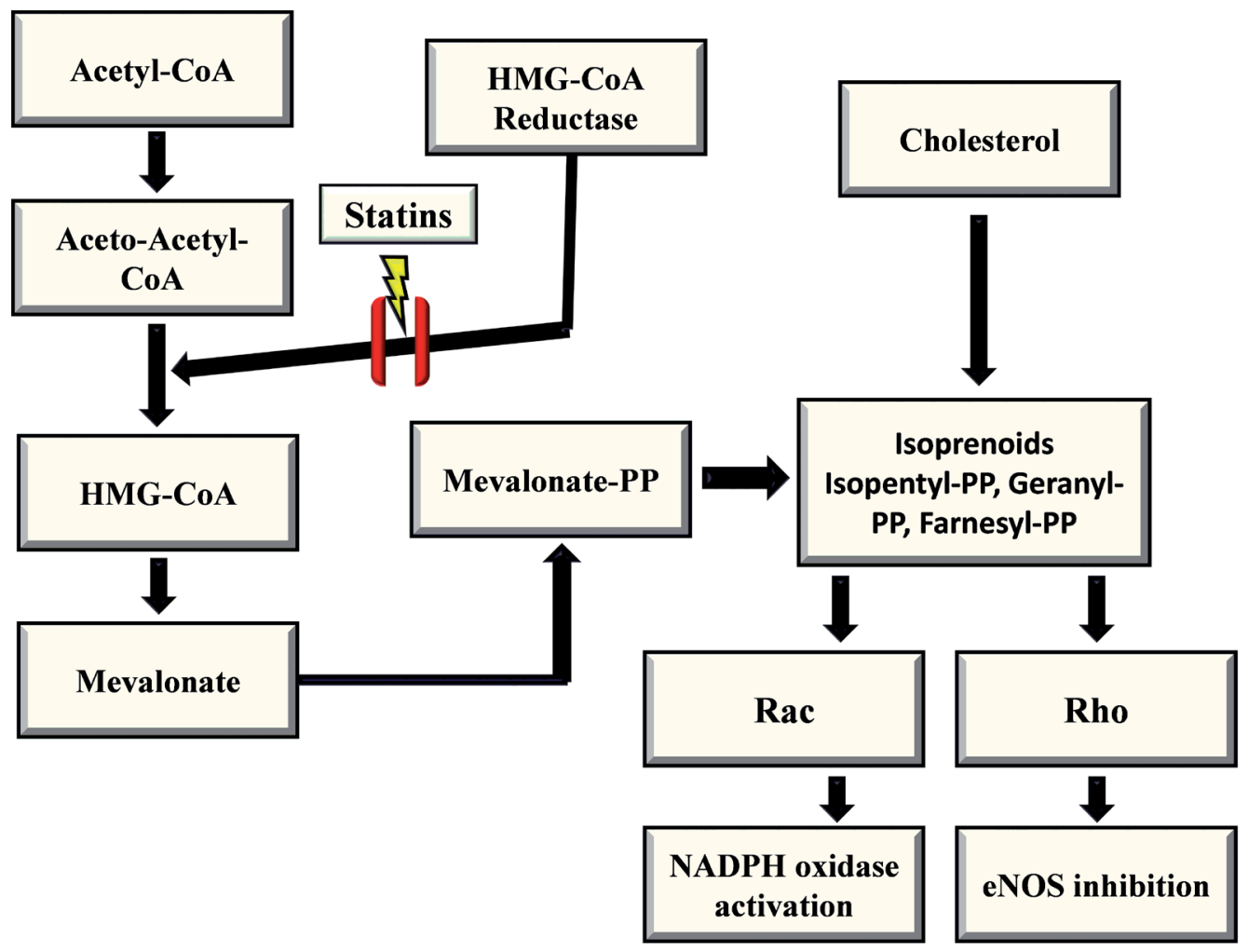

Figure 2: Overview of the mechanism of action of statins. Statins interfere with the mevalonate synthesis pathway by inhibiting the action of the enzyme HMG-CoA. This inhibition results in reduced cholesterol as well as other several isoprenoid molecule synthesis, attenuation of Rac and Rho isoprenylation and subsequent reduction in Rac mediated NADPH oxidase activity and Rho mediated increase in eNOS activity, thus improving NO bioavailability in endothelial cells.

Abbreviations: eNOS: endothelial nitric oxide synthase, NADPH: Nicotinamide adenine dinucleotide phosphate, PP: pyrophosphate.

\section{STATINS AND THEIR PLEIOTROPIC ACTIONS}

The most promising available therapy for treating CVD are the 3-hydroxy-3-methyl-glutaryl-CoA-reductase (HMG-CoA) reductase inhibitors which are better known as statins (Table 1). Apart from the direct lipid lowering effects due to inhibition of the mevalonate pathway, which is involved in cholesterol synthesis in the liver (Figure 2), it has now been confirmed by a large number of clinical trials (Table 2) that statins also exert several pleiotropic effects and can be used in both primary and secondary preventive interventions. Indeed, this highlights the unique role of statins in both primary and secondary preventive measures.

Interestingly, statins have been found to affect adhesion molecule expression. For example, lymphocyte function-associated antigen-1 (LFA-1), a part of the $\beta 2$ integrin sub-family, has been found to be blocked by lovastatin and more potently by its derivatives without affecting HMG-CoA reductase. LFA-1 plays an important role in both lymphocyte and leukocyte functions
[66-67]. Fluvastatin treatment demonstrated reduced levels of P-selectin and ICAM-1 in patients with hypercholesterolemia [68]. Atorvastatin and simvastatin were found to have similar effects in markedly reducing soluble E- and P- selectin as well as ICAM-1, although in the case of simvastatin this effect was accompanied with an increase in soluble VCAM-1 [69].

Statins have been also associated with regulation of pro-inflammatory cytokine expression. Studies performed in vivo and in vitro have revealed that simvastatin reduced the levels of IL-8, IL-6 and monocyte chemoattractant protein-1 (MCP-1) in circulating monocytes from patients with hypercholesterolaemia [70]. Furthermore, statins have been also found to down-regulate several MMPs, which contributes to their overall anti-inflammatory and cardio-protective effects [71].

Direct anti-oxidant effects are mostly dependent on the structural properties of statins. In a comparative in-vitro study of several statins, all demonstrated anti-oxidant functions, however there were still signifi- 
Table 2. Overview of high impact clinical trials with statins for primary and secondary prevention.

\begin{tabular}{|c|c|c|c|c|}
\hline Study name & Aim of study & Population & Intervention & Outcome \\
\hline $\begin{array}{l}\text { A to } Z \text { trial } \\
{[78]}\end{array}$ & $\begin{array}{c}\text { Secondary prevention, pa- } \\
\text { tients with acute coronary } \\
\text { syndrome }\end{array}$ & 4,497 ACS patients & $\begin{array}{l}\text { Simvastatin } 40 \mathrm{mg} / \mathrm{d} \\
\text { for } 1 \mathrm{~m} \text { and then } \\
80 \mathrm{mg} / \mathrm{d} \text { vs. placebo } \\
\text { for } 4 \mathrm{~m} \text { and then } \\
\text { simvastatin } 20 \mathrm{mg} / \mathrm{d}\end{array}$ & $\begin{array}{l}\text { Intensive simvastatin } \\
\text { treatment demonstrated } \\
\text { a favorable trend toward } \\
\text { reduction of MACE }\end{array}$ \\
\hline $\begin{array}{l}\text { ALLHAT-LLT } \\
{[79]}\end{array}$ & $\begin{array}{l}\text { Secondary prevention in } \\
\text { patients with or at high } \\
\text { risk for developing Coro- } \\
\text { nary Heart Disease }\end{array}$ & $\begin{array}{c}\text { 10,355 hypercholester- } \\
\text { olemic, hypertensive } \\
\text { patients (>55 y) with at } \\
\text { least } 1 \text { additional CHD } \\
\text { risk factor }\end{array}$ & $\begin{array}{l}\text { Pravastatin } 40 \mathrm{mg} / \mathrm{d} \\
\text { vs. usual care }\end{array}$ & $\begin{array}{c}\text { No effect on all-cause mor- } \\
\text { tality nor CHD }\end{array}$ \\
\hline $\begin{array}{l}\text { ASCOT-LLA } \\
{[80]}\end{array}$ & $\begin{array}{l}\text { Secondary prevention in } \\
\text { Patients with or at high } \\
\text { risk for developing Coro- } \\
\text { nary Heart Disease }\end{array}$ & $\begin{array}{c}\text { 10,305 hypertensive } \\
\text { patients, with at least } \\
3 \text { other risk factors for } \\
\text { CHD }\end{array}$ & $\begin{array}{l}\text { Atorvastatin } 10 \mathrm{mg} / \mathrm{d} \\
\text { vs. placebo }\end{array}$ & $\begin{array}{l}\text { Reduced risk for primary } \\
\text { events }(\mathrm{HR}=0.64 ; 95 \% \mathrm{Cl} \\
\quad 0.50-0.83)\end{array}$ \\
\hline $\begin{array}{l}\text { CORONA } \\
{[81]}\end{array}$ & $\begin{array}{c}\text { Secondary prevention, } \\
\text { patients with Heart Failure }\end{array}$ & $\begin{array}{c}\text { 5,011 ischemic, sys- } \\
\text { tolic HF patients ( } \geq 60 \text { y, } \\
\text { NYHA II- IV) }\end{array}$ & $\begin{array}{l}\text { Rosuvastatin } 10 \mathrm{mg} / \mathrm{d} \\
\text { vs. placebo }\end{array}$ & $\begin{array}{l}\text { No difference in coronary } \\
\text { events or death. }\end{array}$ \\
\hline HPS [82] & $\begin{array}{c}\text { Secondary prevention, pa- } \\
\text { tients with stable coronary } \\
\text { disease }\end{array}$ & $\begin{array}{l}\text { 20,536 patients with } \\
\text { CHD, occlusive arterial } \\
\text { disease, ordiabetes }\end{array}$ & $\begin{array}{l}\text { Simvastatin vs. } \\
\text { placebo }\end{array}$ & $\begin{array}{l}\text { Simvastatin reduced all } \\
\text { cause and coronary mor- } \\
\text { tality, and vascular } \\
\text { events by } 24 \%(95 \% \mathrm{Cl} \\
19-28 \%)\end{array}$ \\
\hline JUPITER [83] & Primary prevention & $\begin{array}{c}17,802 \text { subjects } \\
(\mathrm{LDL}<130 \mathrm{mg} / \mathrm{dL} \\
\mathrm{CRP}>2.0 \mathrm{mg} / \mathrm{L}\end{array}$ & $\begin{array}{l}\text { Rosuvastatin vs. } \\
\text { placebo }\end{array}$ & $\begin{array}{l}\text { Rosuvastatin reduced risk } \\
\text { for MACEs }(\mathrm{HR}=0.56 ; 95 \% \\
\qquad \mathrm{Cl}, 0.46-0.69)\end{array}$ \\
\hline LIPID [84] & $\begin{array}{c}\text { Secondary prevention, pa- } \\
\text { tients with stable coronary } \\
\text { disease }\end{array}$ & 9,014 CHD patients & $\begin{array}{l}\text { Pravastatin vs. pla- } \\
\text { cebo }\end{array}$ & $\begin{array}{l}\text { Pravastatin reduced coro- } \\
\text { nary mortality risk by } 24 \% \\
(95 \% \mathrm{Cl}, 12-35 \%)\end{array}$ \\
\hline $\begin{array}{l}\text { WOSCOPS } \\
{[85]}\end{array}$ & Primary prevention & 6,595 men without CHD & $\begin{array}{l}\text { Pravastatin vs. pla- } \\
\text { cebo }\end{array}$ & $\begin{array}{l}\text { Pravastatin reduced } \\
\text { coronary events by 31\% } \\
\text { (95\%Cl, } 17-43 \%) \text { and } \\
\text { coronary mortality by } \\
32 \%(95 \% \mathrm{Cl}, 3-53 \%)\end{array}$ \\
\hline
\end{tabular}

Abbreviations: ACS: Acute coronary syndrome, CHD: Coronary heart disease, CRP: C-reactive protein, d: day LDL: Low density lipoprotein, m: Months, MACE: Major adverse cardiac events, w: weeks, y: years.

cant differences in the potency and the type of radicals that are scavenged [72]. Studies showed that fluvastatin had a greater capability for scavenging peroxyl radicals whereas simvastatin showed a superior capability for scavenging for hydroxyl radicals [72]. Another important parameter for the anti-oxidant effects of statins is the target substrate. Fluvastatin treatment in rat liver microsomes offered protection from NADPH-mediated lipid peroxidation whereas pravastatin demonstrated a much weaker effect. In a similar study, atorvastatin was more effective in inhibiting hydroperoxide formation compared to vitamin $\mathrm{E}$ for a prolonged period of time [73]. Ample data exists verifying that statins can modulate NADPH oxidase enzyme activity thus attenuating ROS production and exerting an antioxidant effects. This is mostly mediated through inhibition of rac-1 translocation, a critical component for the activity of NADPH oxidase [74]. Our studies revealed that short-term treatment with $40 \mathrm{mg}$ of atorvastatin per day before coronary artery bypass graft, inhibits vascular Rac1-mediated activation of NOX independently of LDL levels thus improving redox state in saphenous vein grafts [75]. Furthermore, daily administration of atorvastatin at the same dose, had a direct effect in arte- 
rial redox state by improving NO bioavailability, while reducing eNOS derived- $\mathrm{O}_{2}$ - in humans [76-77].

Statins also have distinct direct effects on several anti-oxidant enzymes. Atorvastatin and lovastatin increase catalase synthesis, while rosuvastatin increases glutathione synthesis. There are also reports that pitavastatin directly inhibits ROS formation in endothelial cells [74].

\section{CONCLUSIONS}

As knowledge regarding the pathophysiology of CVD increases, it is becoming more obvious that atherosclerosis, the major underlying cause of CVD, represents a multivariable disease with several molecules and signalling pathways actively involved in each stage of this process. While this makes treatment a much more complicated issue, it also offers a wide range of potential therapeutic approaches. Statins have so far proven to offer the best "anti-inflammatory" and "antioxidant" solution in humans since they have direct effects on most of the critical pathways involved in the disease progress. It is certain that they will remain the spearhead for combating CVD and atherosclerosis in the near future.

\section{GINANCIAL DECLARATION}

None declared

\section{CONFLICT OF INTEREST}

None declared

\section{LIST OF ABBREVIATIONS}

ADMA: Asymmetrical Dimethylarginine

AMI: Acute myocardial infraction

$\mathrm{BH}_{2}$ : Dihydrobiopterin

$\mathrm{BH}_{4}: \quad$ Tetrahydrobiopterin

CAD: Coronary artery disease

CHD: Coronary heart disease

COP: CARD-only protein

CVD: Cardiovascular disease

EC: $\quad$ Endothelial cells

eNOS: Endothelial nitric oxide synthase

GTPCH: Guanosine triphosphate cyclohydrolase
HDL: High density lipoprotein

Hs-CRP: High sensitivity C-reactive protein

ICAM: Intracellular adhesion molecule

IL-10: Interleukin-10

IL-1 $\beta$ : Interleukin-1 $\beta$

IL-6: $\quad$ Interleukin-6

JAM: Junctional adhesion molecule

LFA-1: Lymphocyte function-associated antigen-1

Lp-PLA 2 : Lipoprotein-associated phospholipase A2

MCP-1: Monocyte chemoattractant protein-1

MDA: Malondialdehyde

mmLDL: Minimally modified LDL

NADPH: Nicotinamide adenine dinucleotide phosphate

NO: $\quad$ Nitric oxide

ONOO:: Peroxynitrite

Ox-LDL: Oxidized low density lipoprotein

PAF-AH: Platelet-activating factor acetylhydrolase

PECAM-1: Platelet endothelial cell adhesion molecule-1

PI-9: $\quad$ Proteinase inhibitor 9

ROS: Reactive oxygen species

SAA: $\quad$ Serum amyloid A

sVCAM-1:Soluble vascular cell adhesion molecule-1

TNF: Tumor necrosis factor

VCAM-1: Vascular cell adhesion molecule-1

VLA-4: Very late antigen-4

VSMC: Vascular smooth muscle cell

\section{DEFERENCES}

1. Lee R, Margaritis M, Channon KM, et al. Evaluating oxidative stress in human cardiovascular disease: methodological aspects and considerations. Curr Med Chem. 2012;19:2504-20.

2. Tousoulis D, Psarros C, Demosthenous M, et al. Innate and adaptive inflammation as a therapeutic target in vascular disease: the emerging role of statins. J Am Coll Cardiol. 2014;63:2491-502.

3. Psarros C, Lee $R$, Margaritis $M$, et al. Nanomedicine for the prevention, treatment and imaging of atherosclerosis. Nanomedicine. 2012;8 Suppl 1:S59-68.

4. Antoniades C, Antonopoulos AS, Tousoulis D, et al. Adiponectin: from obesity to cardiovascular disease. Obes Rev. 2009;10:26979.

5. Antonopoulos AS, Lee R, Margaritis M, et al. Adiponectin as 
a regulator of vascular redox state: therapeutic implications. Recent Pat Cardiovasc Drug Discov. 2011;6:78-88.

6. Margaritis M, Antonopoulos AS, Digby J, et al. Interactions between vascular wall and perivascular adipose tissue reveal novel roles for adiponectin in the regulation of endothelial nitric oxide synthase function in human vessels. Circulation. 2013;127:2209-21.

7. Antonopoulos AS, Margaritis M, Coutinho P, et al. Adiponectin As A Link Between Type 2 Diabetes Mellitus And Vascular NADPH-Oxidase Activity In The Human Arterial Wall: The Regulatory Role Of Perivascular Adipose Tissue. Diabetes. 2014. doi: 10.2337/db14-1011 [Epub ahead of print]

8. Channon KM and Guzik TJ. Mechanisms of superoxide production in human blood vessels: relationship to endothelial dysfunction, clinical and genetic risk factors. J Physiol Pharmacol. 2002;53:515-24.

9. Alp NJ, Mussa S, Khoo J, et al. Tetrahydrobiopterin-dependent preservation of nitric oxide-mediated endothelial function in diabetes by targeted transgenic GTP-cyclohydrolase I overexpression. J Clin Invest. 2003;112:725-35.

10.Cunnington C, Van Assche T, Shirodaria C, et al. Systemic and Vascular Oxidation Limits the Efficacy of Oral Tetrahydrobiopterin Treatment in Patients With Coronary Artery Disease. Circulation. 2012;125:1356-66.

11.Landmesser U, Hornig B, Drexler H. Endothelial function: a critical determinant in atherosclerosis? Circulation. 2004;109:||27-33.

12.Antoniades C, Tousoulis D, Vasiliadou C, et al. Genetic polymorphism on endothelial nitric oxide synthase affects endothelial activation and inflammatory response during the acute phase of myocardial infarction. J Am Coll Cardiol. 2005;46:1101-9.

13.Antoniades C, Shirodaria C, Warrick N, et al. 5-methyltetrahydrofolate rapidly improves endothelial function and decreases superoxide production in human vessels: effects on vascular tetrahydrobiopterin availability and endothelial nitric oxide synthase coupling. Circulation. 2006;114:1193-201.

14.Antoniades C, Shirodaria C, Leeson P, et al. Association of plasma asymmetrical dimethylarginine (ADMA) with elevated vascular superoxide production and endothelial nitric oxide synthase uncoupling: implications for endothelial function in human atherosclerosis. Eur Heart J. 2009;30:1142-50.

15.Gounari P, Tousoulis D, Antoniades C, et al. Rosuvastatin but not ezetimibe improves endothelial function in patients with heart failure, by mechanisms independent of lipid lowering. Int J Cardiol. 2010;142:87-91.

16.Antoniades C, Demosthenous M, Tousoulis D, et al. Role of asymmetrical dimethylarginine in inflammation-induced endothelial dysfunction in human atherosclerosis. Hypertension. 2011;58:93-8.

17.Ait-Oufella H, Taleb S, Mallat Z, et al. Recent advances on the role of cytokines in atherosclerosis. Arterioscler Thromb Vasc Biol. 2011;31:969-79.

18. Tousoulis D, Antoniades C, Stefanadis C. Assessing inflammatory status in cardiovascular disease. Heart. 2007;93:1001-7.

19.Kim JH, Bachmann RA, Chen J. Interleukin-6 and insulin resistance. Vitam Horm. 2009;80:613-33.

20.Schuett H, Luchtefeld M, Grothusen C, et al. How much is too much? Interleukin-6 and its signalling in atherosclerosis. Thromb Haemost. 2009;102:215-22.

21.Abeywardena MY, Leifert WR, Warnes KE, et al. Cardiovascular biology of interleukin-6. Curr Pharm Des. 2009;15:1809-21.

22.Yudkin JS, Kumari M, Humphries SE, et al. Inflammation, obesity, stress and coronary heart disease: is interleukin-6 the link? Atherosclerosis. 2000;148:209-14.

23. Hartge MM, Unger T, Kintscher $U$. The endothelium and vascular inflammation in diabetes. Diab Vasc Dis Res. 2007;4:84-8.

24. Wang Z, Castresana MR, Newman WH. Reactive oxygen and NFkappaB in VEGF-induced migration of human vascular smooth muscle cells. Biochem Biophys Res Commun. 2001;285:669-74.

25.Church LD, Cook GP, McDermott MF. Primer: inflammasomes and interleukin 1 beta in inflammatory disorders. Nat Clin Pract Rheumatol. 2008;4:34-42.

26.Schmitz J, Owyang A, Oldham E, et al. IL-33, an interleukin-1-like cytokine that signals via the IL-1 receptor-related protein ST2 and induces $T$ helper type 2-associated cytokines. Immunity. 2005;23:479-90.

27. Okamura H, Tsutsui H, Kashiwamura S, et al. Interleukin-18: a novel cytokine that augments both innate and acquired immunity. Adv Immunol. 1998;70:281-312.

28. Pizarro TT, Cominelli F. Cloning IL-1 and the birth of a new era in cytokine biology. J Immunol. 2007;178:5411-2.

29.Asadullah K, Sterry W, Volk HD. Interleukin-10 therapy--review of a new approach. Pharmacol Rev. 2003;55:241-69.

30. Han X, Kitamoto S, Wang H, et al. Interleukin-10 overexpression in macrophages suppresses atherosclerosis in hyperlipidemic mice. FASEB J. 2010;24:2869-80.

31.Han X, Kitamoto S, Lian Q, et al. Interleukin-10 facilitates both cholesterol uptake and efflux in macrophages. J Biol Chem. 2009;284:32950-8.

32.Gracie JA, Robertson SE, McInnes IB. Interleukin-18. J Leukoc Biol. 2003;73:213-24.

33. Blankenberg S, Tiret L, Bickel C, et al. Interleukin-18 is a strong predictor of cardiovascular death in stable and unstable angina. Circulation. 2002;106:24-30.

34.Tziakas DN, Chalikias GK, Kaski JC, et al. Inflammatory and anti-inflammatory variable clusters and risk prediction in acute coronary syndrome patients: a factor analysis approach. Atherosclerosis. 2007;193:196-203.

35.Lin S, Lee CK, Wang YM, et al. Measurement of dimensions of pentagonal doughnut-shaped C-reactive protein using an atomic force microscope and a dual polarisation interferometric biosensor. Biosens Bioelectron. 2006;22:323-7.

36.Calabro P, Willerson JT, Yeh ET. Inflammatory cytokines stimulated C-reactive protein production by human coronary artery smooth muscle cells. Circulation. 2003;108:1930-2. 
Available online at: www.jccm.ro

37.Venugopal SK, Devaraj S, Jialal I. Macrophage conditioned medium induces the expression of C-reactive protein in human aortic endothelial cells: potential for paracrine/autocrine effects. Am J Pathol. 2005;166:1265-71.

38.Pepys MB, Hirschfield GM. C-reactive protein: a critical update. J Clin Invest. 2003;111:1805-12.

39. Rifai N, Ridker PM. Proposed cardiovascular risk assessment algorithm using high-sensitivity C-reactive protein and lipid screening. Clin Chem. 2001;47:28-30.

40.Elkind MS. Inflammation, atherosclerosis, and stroke. Neurologist. 2006;12:140-8.

41.King VL, Thompson J, Tannock LR. Serum amyloid A in atherosclerosis. Curr Opin Lipidol. 2011;22:302-7.

42. Rho YH, Chung CP, Oeser A, et al. Novel cardiovascular risk factors in premature coronary atherosclerosis associated with systemic lupus erythematosus. J Rheumatol. 2008;35:1789-94.

43. Min JH, Jain MK, Wilder C, et al. Membrane-bound plasma platelet activating factor acetylhydrolase acts on substrate in the aqueous phase. Biochemistry. 1999;38:12935-42.

44.Wilensky RL and Macphee $\mathrm{CH}$. Lipoprotein-associated phospholipase $A(2)$ and atherosclerosis. Curr Opin Lipidol. 2009;20:415-20.

45.Anderson JL. Lipoprotein-associated phospholipase A2: an independent predictor of coronary artery disease events in primary and secondary prevention. Am J Cardiol. 2008;101:23F-33F.

46. Blankenberg S, Barbaux S, Tiret L. Adhesion molecules and atherosclerosis. Atherosclerosis. 2003;170:191-203.

47. McEver RP. Selectins: lectins that initiate cell adhesion under flow. Curr Opin Cell Biol. 2002;14:581-6.

48.Galkina E, Kadl A, Sanders J, et al. Lymphocyte recruitment into the aortic wall before and during development of atherosclerosis is partially L-selectin dependent. J Exp Med. 2006;203:1273-82.

49. Eriksson EE, Xie X, Werr J, et al. Importance of primary capture and L-selectin-dependent secondary capture in leukocyte accumulation in inflammation and atherosclerosis in vivo. J Exp Med. 2001;194:205-18.

50.Galkina $E$ and Ley $K$. Vascular adhesion molecules in atherosclerosis. Arterioscler Thromb Vasc Biol. 2007;27:2292301.

51.Paez A, Mendez-Cruz AR, Varela E, et al. HUVECs from newborns with a strong family history of myocardial infarction overexpress adhesion molecules and react abnormally to stimulating agents. Clin Exp Immunol. 2005;141:449-58.

52.Davies MJ, Gordon JL, Gearing AJ, et al. The expression of the adhesion molecules ICAM-1, VCAM-1, PECAM, and E-selectin in human atherosclerosis. J Pathol. 1993;171:223-9.

53.Yu G, Rux AH, Ma P, et al. Endothelial expression of E-selectin is induced by the platelet-specific chemokine platelet factor 4 through LRP in an NF-kappaB-dependent manner. Blood. 2005;105:3545-51.

54. Hafezi-Moghadam A, Thomas KL, Prorock AJ, et al. L-selectin
The Journal of Critical Care Medicine 2015;1(2) • 53

shedding regulates leukocyte recruitment. J Exp Med. 2001;193:863-72.

55.del Pozo MA, Pulido R, Munoz C, et al. Regulation of ICAM-3 (CD50) membrane expression on human neutrophils through a proteolytic shedding mechanism. Eur J Immunol. 1994;24:258694.

56. Kostidou E, Topouridou K, Danilidis A, et al. Oxidized laminin-1 induces increased monocyte attachment and expression of ICAM-1 in endothelial cells. Int J Exp Pathol. 2009;90:630-7.

57. Matheny HE, Deem TL, Cook-Mills JM. Lymphocyte migration through monolayers of endothelial cell lines involves VCAM1 signaling via endothelial cell NADPH oxidase. J Immunol. 2000;164:6550-9.

58. Malik I, Danesh J, Whincup P, et al. Soluble adhesion molecules and prediction of coronary heart disease: a prospective study and meta-analysis. Lancet. 2001;358:971-6.

59. Woodfin A, Voisin MB, Nourshargh S. PECAM-1: a multifunctional molecule in inflammation and vascular biology. Arterioscler Thromb Vasc Biol. 2007;27:2514-23.

60.Wong CW, Wiedle G, Ballestrem C, et al. PECAM-1/CD31 transhomophilic binding at the intercellular junctions is independent of its cytoplasmic domain; evidence for heterophilic interaction with integrin alphavbeta3 in Cis. Mol Biol Cell. 2000;11:3109-21.

61. Mandell KJ, Parkos CA. The JAM family of proteins. Adv Drug Deliv Rev. 2005;57:857-67.

62.Babinska A, Azari BM, Salifu MO, et al. The F11 receptor (F11R/JAM-A) in atherothrombosis: overexpression of F11R in atherosclerotic plaques. Thromb Haemost. 2007;97:272-81.

63. Ostermann G, Fraemohs L, Baltus T, et al. Involvement of JAM-A in mononuclear cell recruitment on inflamed or atherosclerotic endothelium: inhibition by soluble JAM-A. Arterioscler Thromb Vasc Biol. 2005;25:729-35.

64.Zernecke A, Liehn EA, Fraemohs L, et al. Importance of junctional adhesion molecule-A for neointimal lesion formation and infiltration in atherosclerosis-prone mice. Arterioscler Thromb Vasc Biol. 2006;26:e10-3.

65.Keiper T, Al-Fakhri N, Chavakis E, et al. The role of junctional adhesion molecule-C (JAM-C) in oxidized LDL-mediated leukocyte recruitment. FASEB J. 2005;19:2078-80.

66. Weitz-Schmidt G. Lymphocyte function-associated antigen-1 blockade by statins: molecular basis and biological relevance. Endothelium. 2003;10:43-7.

67. Welzenbach K, Hommel U, Weitz-Schmidt G. Small molecule inhibitors induce conformational changes in the I domain and the I-like domain of lymphocyte function-associated antigen-1. Molecular insights into integrin inhibition. J Biol Chem. 2002;277:10590-8.

68. Romano M, Mezzetti A, Marulli C, et al. Fluvastatin reduces soluble P-selectin and ICAM-1 levels in hypercholesterolemic patients: role of nitric oxide. J Investig Med. 2000;48:183-9.

69.Seljeflot I, Tonstad S, Hjermann I, et al. Reduced expression of endothelial cell markers after 1 year treatment with simvastatin and atorvastatin in patients with coronary heart disease. 
Atherosclerosis. 2002;162:179-85.

70. Rezaie-Majd A, Maca T, Bucek RA, et al. Simvastatin reduces expression of cytokines interleukin-6, interleukin-8, and monocyte chemoattractant protein-1 in circulating monocytes from hypercholesterolemic patients. Arterioscler Thromb Vasc Biol. 2002;22:1194-9.

71.Izidoro-Toledo TC, Guimaraes DA, Belo VA, et al. Effects of statins on matrix metalloproteinases and their endogenous inhibitors in human endothelial cells. Naunyn Schmiedebergs Arch Pharmacol. 2011;383:547-54.

72.Franzoni F, Quinones-Galvan A, Regoli F, et al. A comparative study of the in vitro antioxidant activity of statins. Int J Cardiol. 2003;90:317-21.

73.Davignon J, Jacob RF, Mason RP. The antioxidant effects of statins. Coron Artery Dis. 2004;15:251-8.

74. Lim S, Barter P. Antioxidant effects of statins in the management of cardiometabolic disorders. J Atheroscler Thromb. 2014;21:997-1010.

75.Antoniades C, Bakogiannis C, Tousoulis D, et al. Preoperative atorvastatin treatment in CABG patients rapidly improves vein graft redox state by inhibition of Rac1 and NADPH-oxidase activity. Circulation. 2010;122:S66-73.

76.Antoniades C, Bakogiannis C, Leeson P, et al. Rapid, direct effects of statin treatment on arterial redox state and nitric oxide bioavailability in human atherosclerosis via tetrahydrobiopterinmediated endothelial nitric oxide synthase coupling. Circulation. 2011;124:335-45.

77.Antonopoulos AS, Margaritis M, Shirodaria C, et al. Translating the effects of statins: from redox regulation to suppression of vascular wall inflammation. Thromb Haemost. 2012;108:840-8.

78. de Lemos JA, Blazing MA, Wiviott SD, et al. Early intensive vs a delayed conservative simvastatin strategy in patients with acute coronary syndromes: phase $Z$ of the $A$ to $Z$ trial. JAMA. 2004;292:1307-16.

79.Officers A, Coordinators for the ACRGTA, Lipid-Lowering Treatment to Prevent Heart Attack T. Major outcomes in moderately hypercholesterolemic, hypertensive patients randomized to pravastatin vs usual care: The Antihypertensive and Lipid-Lowering Treatment to Prevent Heart Attack Trial (ALLHAT-LLT). JAMA. 2002;288:2998-3007.

80.Sever PS, Dahlof B, Poulter NR, et al. Prevention of coronary and stroke events with atorvastatin in hypertensive patients who have average or lower-than-average cholesterol concentrations, in the Anglo-Scandinavian Cardiac Outcomes Trial--Lipid Lowering Arm (ASCOT-LLA): a multicentre randomised controlled trial. Lancet. 2003;361:1149-58.

81.Kjekshus J, Apetrei E, Barrios V, et al. Rosuvastatin in older patients with systolic heart failure. N EngI J Med. 2007;357:224861.

82. Heart Protection Study Collaborative G. MRC/BHF Heart Protection Study of cholesterol lowering with simvastatin in 20,536 high-risk individuals: a randomised placebo-controlled trial. Lancet. 2002;360:7-22.

83.Ridker PM, Danielson E, Fonseca FA, et al. Rosuvastatin to prevent vascular events in men and women with elevated C-reactive protein. N Engl J Med. 2008;359:2195-207.

84.Prevention of cardiovascular events and death with pravastatin in patients with coronary heart disease and a broad range of initial cholesterol levels. The Long-Term Intervention with Pravastatin in Ischaemic Disease (LIPID) Study Group. N Engl J Med. 1998;339:1349-57.

85. Shepherd J, Cobbe SM, Ford I, et al. Prevention of coronary heart disease with pravastatin in men with hypercholesterolemia. West of Scotland Coronary Prevention Study Group. N Engl J Med. 1995;333:1301-7. 